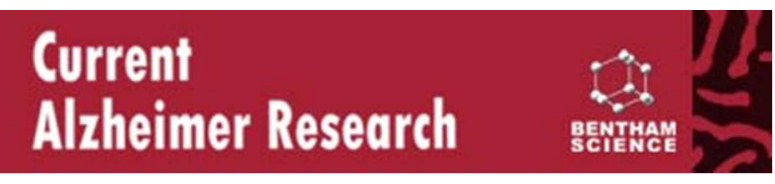

\title{
The long non-coding RNAs in neurodegenerative diseases: novel mechanisms of pathogenesis
}

\begin{tabular}{|r|l|}
\hline Journal: & Current Alzheimer Research \\
\hline Manuscript ID & CAR-2015-0161.R1 \\
\hline Manuscript Type: & Invited Review \\
\hline Date Submitted by the Author: & 08-Apr-2016 \\
\hline Complete List of Authors: & $\begin{array}{l}\text { Riva, Paola; Università degli Studi di Milano, Department of Medical } \\
\text { Biotechnology and Translational Medicine } \\
\text { Ratti, Antonia; Università degli Studi di Milano, Department of } \\
\text { Pathophysiology and Transplantation; IRCCS Istituto Auxologico Italiano } \\
\text { Venturin, Marco; Università degli Studi di Milano, Department of Medical } \\
\text { Biotechnology and Translational Medicine }\end{array}$ \\
\hline Keywords: & $\begin{array}{l}\text { IncRNA, neurodegenerative diseases, post-transcriptional regulation, } \\
\text { pathogenetic mechanisms, IncRNA nuclear activity, IncRNA cytoplasmic } \\
\text { activity }\end{array}$ \\
\hline \multicolumn{2}{|l}{} \\
\hline
\end{tabular}


1

2

3

4

5

6

7

8

9

10

11

12

13

14

15

16

17

18

19

20

21

22

23

24

25

26

27

28

29

30

31

32

33

34

35

36

37

38

39

40

41

42

43

44

45

46

47

48

49

50

51

52

53

54

55

56

57

58

59

60

The long non-coding RNAs in neurodegenerative diseases: novel mechanisms of pathogenesis

Paola Riva ${ }^{1}$, Antonia Ratti ${ }^{2,3}$ and Marco Venturin ${ }^{1}$

${ }^{1}$ Dipartimento di Biotecnologie Mediche e Medicina Traslazionale - Università degli Studi di Milano, Milano, Italy

${ }^{2}$ Dipartimento di Fisiopatologia Medico-Chirurgica e dei Trapianti - Università degli Studi di Milano, Milano, Italy

${ }^{3}$ IRCCS Istituto Auxologico Italiano, Milano, Italy

RUNNING TITLE: The IncRNAs in neurodegenerative mechanisms

KEYWORDS: IncRNA, neurodegenerative diseases, post-transcriptional regulation, pathogenetic mechanisms, IncRNA nuclear activity, IncRNA cytoplasmic activity

CORRESPONDING AUTHOR: Paola Riva PhD

Dipartimento di Biotecnologie Mediche e Medicina Traslazionale Università degli Studi di Milano Via Viotti 3/5

20133 Milan - Italy

e-mail:paola.riva@unimi.it 


\section{ABSTRACT}

Background: Long-non-coding RNAs (IncRNAs), RNA molecules longer than 200 nucleotides, have been involved in several biological processes and in a growing number of diseases, controlling gene transcription, pre-mRNA processing, the transport of mature mRNAs to specific cellular compartments, the regulation of mRNA stability, protein translation and turnover. The fundamental role of IncRNAs in central nervous system (CNS) is becoming increasingly evident. LncRNAs are abundantly expressed in mammalian CNS in a specific spatio-temporal manner allowing a quick response to environmental/molecular changes. Methods: This article reviews the biology and mechanisms of action of IncRNAs underlying their potential role in CNS and in some neurodegenerative diseases. Results: an increasing number of studies report on IncRNAs involvement in different molecular mechanisms of gene expression modulation in CNS, from neural stem cell differentiation mainly by chromatin remodeling, to control of neuronal activities. More recently, IncRNAs have been implicated in neurodegenerative diseases, including Alzheimer's Disease, where the role of BACE1-AS InCRNA has been widely defined. BACE1-AS levels are up-regulated in AD brains where BACE1-AS acts by stabilizing BACE1 mRNA thereby increasing BACE1 protein content and $A \beta 42$ formation. In Frontotemporal dementia and Amyotrophic lateral sclerosis the IncRNAs NEAT1_2 and MALAT1 colocalize at nuclear paraspeckles with TDP-43 and FUS proteins and their binding to TDP-43 is markedly increased in affected brains. In Parkinson's Disease the InCRNA UCHL1-AS1 acts by directly promoting translation of UCHL1 protein leading to perturbation of the ubiquitin-proteasome system. Different IncRNAs, such as HTT-AS, BDNF-AS and HAR1, were found to be dysregulated in their expression also in Huntington's Disease. In Fragile X syndrome (FXS) and Fragile X tremor/ataxia syndrome (FXTAS) patients, the presence of CGG repeats expansion alters the expression of the IncRNAs FMR1-AS1 and FMR6. Interestingly, they are expressed in peripheral blood leukocytes, suggesting these IncRNAs may represent biomarkers for FXS/FXTAS early detection and therapy. Finally, the identification of the antisense RNAs SCAANT1-AS and ATXN8OS in spinocerebellar ataxia 7 and 8, respectively, suggests that very different mechanisms of action driven by IncRNAs may trigger neurodegeneration in these disorders.

The emerging role of IncRNAs in neurodegenerative diseases suggests that their dysregulation could trigger neuronal death via still unexplored RNA-based regulatory mechanisms which deserve further investigation. The evaluation of their diagnostic significance and therapeutic potential could also address the setting up of novel treatments in diseases where no cure is available to date. 


\section{INTRODUCTION}

Neurodegenerative disorders, in particular Alzheimer's disease (AD) and Parkinson's disease (PD), are increasing to epidemic proportions and, although the efforts carried out in the last decade by scientific community revealed important insights into their molecular bases, their etiology remains elusive. This condition reflects the high complexity of human brain biology. Since the great difference in cognitive abilities between humans and invertebrates is not correlated to a correspondent difference in the number of protein coding genes, it is more and more evident that additional mechanisms regulating alternative splicing and gene expression both at transcriptional and post-transcriptional levels play an important role in the development and function of the central nervous system (CNS) [1]. The fundamental role of non-coding RNAs (ncRNAs) in the fine regulation of gene expression in CNS, via control of nuclear processing of primary transcripts, transport of mature mRNAs to specific cellular compartments, as well as regulation of mRNA stability, translation and turnover, has become increasingly evident. The regulatory function of different classes of ncRNAs, such as microRNAs (miRNAs), piwi-interacting RNAs (piRNAs) and, more recently, longnon coding RNAs (IncRNAs), has been documented in a broad range of biological processes, including cell proliferation, differentiation, apoptosis, development and immune responses [2-4].

While the small ncRNAs have been widely characterized in the last decade as important players in CNS development and functioning and have also been associated to a variety of neurodegenerative diseases [5; 6], the specific functions of the IncRNAs, which have been primarily studied in the context of genomic imprinting, cancer, and cell differentiation, are only recently emerging as pivotal in CNS development and maintenance $[7 ; 8]$.

A possible pathogenetic role of IncRNAs in neurodegenerative diseases has been suggested by the growing number of identified IncRNAs shown to regulate expression of genes involved in the neurodegeneration process or already associated to neurodegenerative disorders. We here report on the functions of IncRNAs and their implication in neurodegenerative diseases, considering their dysregulation as a yet poorly explored pathogenetic mechanism implicated in the neurodegenerative process. Furthermore, the evaluation of their diagnostic significance and therapeutic potential will be discussed, helping to address one of the major challenges in neurobiology, the setting-up of a treatment in diseases where no cure is available to date.

\section{THE InCRNA BIOLOGY}

LncRNAs are defined as RNA molecules longer than 200 nucleotides, generally lacking a protein-coding function [9] and, unlike miRNAs or piRNAs, they are quite heterogeneous, differing in size, interacting partners and mode of action. The estimated number of the human IncRNA genes, reported in the current release of NONCODE Ev4 ID (http://www.noncode.org/analysis.php), is 90.062, a number significantly 
higher than that of coding genes, now amounted to 19.815, according to the current GENCODE version 24 release (http://www.gencodegenes.org/stats/current.html). Localization of IncRNAs is mainly nuclear, but they can also shuttle in the cytoplasm. Although the signals driving cytoplasmic localization are at now unknown [10-12], an RNA motif consisting of the pentamer sequence AGCCC has been recently reported to mediate the nuclear localization of BORG IncRNA [13]. LncRNAs can be broadly classified into two large categories, based on their position in respect to protein-coding genes: 1) intergenic IncRNAs, including pseudogenes, long intergenic non-coding RNAs (lincRNAs), and very long intergenic non-coding RNAs (vlincRNAs/macroRNAs); 2) coding gene-overlapping IncRNAs, represented by intronic IncRNAs, natural antisense transcripts (NATs), expressed non-coding regions (ENORs), enhancer RNAs (eRNAs), and promoter-associated long RNAs (PALRs) [14].

The IncRNA gene structure is similar to that of protein-coding genes, but IncRNAs show a bias for having just one intron and a trend for less efficient co-transcriptional splicing [15; 16]. A proposed mechanism of IncRNA evolution is gene duplication followed by different events leading to non-coding genes that express transcripts endowed with regulatory functions [17]. On the basis of mass spectrometry data reported by Banfai and Derrien, a small fraction (8\%) of the previously annotated IncRNAs was found to produce detectable peptides $[15 ; 18]$. IncRNAs seem to have low translational potential even when ribosomes attempt to decode them. Given that for a number of predicted human protein coding genes no protein experimental data have been provided, we can hypothesize that some human putative IncRNA genes might fall in the group of genes encoding the missing human proteins, estimated to be about $18 \%$ of the human proteome (neXtProt release 19/9/2014). The few previously annotated IncRNA genes expressing transcripts undergoing translation encode small peptides (<100 aminoacids), whose biological significance is mostly unknown $[19 ; 20]$.

The expression of IncRNAs loci show similar features of protein-coding genes: transcription is mainly carried out by RNA polymerase II, splicing occurs using the same consensus signals of coding genes and half of the IncRNAs are 5' capped and 3' polyadenylated. It has been also shown that several IncRNAs may be spliced at their $5^{\prime}$ and $3^{\prime}$ ends generating circular RNAs. However the functional significance of circularization, possibly increasing their stability, has not been yet assessed [21]. Some IncRNAs are known to be transcribed also by RNA polymerase III, but these events cannot be detected using the current whole transcriptome sequencing methods which are based on the enrichment of poly(A)-purified transcripts [22]. This might be a reason why the number of IncRNAs is expected to be higher than that currently estimated. Nevertheless, IncRNAs are on average expressed at a lower level than mRNAs, although variations may occur in the different classes $[11 ; 12]$ and their expression shows a cell-type specificity higher than that of protein coding genes [23]. LncRNA gene expression is believed to be regulated by mechanisms similar to those of protein-coding genes, including control of their synthesis by transcription factors and histone 4 
modifications, and RNA splicing, but this area of IncRNA biology still remains quite unexplored [24-26]. A recent study, integrating ChIP-seq, RNA-seq and based-BRIC-seq RNA half-life data, highlighted how regulation of RNA degradation plays an important role in determining transcript levels of many genes [27]. Similarly, the stability of IncRNAs might have in some cases an important role in their modulation with a consequent effect of IncRNAs post-transcriptional regulatory function [28]. LncRNAs have similar half-life pattern of mRNAs [29]: IncRNAs with short half-lives $(<4 \mathrm{~h})$ have generally a regulatory function, whereas IncRNAs with long half-lives ( $\geq 4 \mathrm{~h}$ ) are involved in housekeeping roles [30]. The stability of IncRNAs seems to be associated with their physiological roles, but this issue was not sufficiently investigated, even if recent studies provided findings addressing the relationship between IncRNA stability and their biological function in specific pathways [31; 32]. The molecular mechanisms regulating IncRNA stability are not well known; the specific RNA decay elements usually located in the 3'UTR of mRNAs, including AU-rich elements (AREs) and Puf family protein-binding sites, were not demonstrated to have a role in IncRNA stability, even if a possible function of predicted AREs should be further investigated [28].

Although IncRNAs selective pressure is between the highest one of coding genes and that of the ancestral repeat sequences, which is considered to be under neutral selection, the promoters of IncRNAs are under very high selective pressure, with levels comparable to the promoters of protein coding genes $[15 ; 25 ; 33-$ 35].

Unlike miRNAs, they are not highly conserved and at now their sequence does not allow to identify consensus sites and associated specific functions, even if high numbers of correlated positions among multiple IncRNA sequence alignments suggest that these regions are under selective pressure to maintain a functional RNA structure [15]. Consistently, mammalian and zebrafish IncRNAs show short stretches of conserved sequence, hence suggesting a functional relevance. Similarly, both location and structure of IncRNAs seem to be conserved, even in the absence of a high sequence conservation [23].

\section{MECHANISMS OF ACTION OF InCRNAS}

LncRNAs, being a large fraction of noncoding transcripts, might represent an important source of molecular regulators in the eukaryotic nucleus, contributing to modulate gene expression at different levels. The role of IncRNAs in the fine tuning of gene expression may quickly respond to changes of environmental conditions or to gene silencing as part of a developmental program [23].

In the last decade an increasing number of studies highlighted the involvement of IncRNAs at all levels of nuclear architecture consistent with DNA replication, transcriptional and post-transcriptional regulatory mechanisms and epigenetic functions. LncRNAs show also important cytoplasmic functions concerning positive and negative regulation of both mRNA and nascent protein stability, regulation of translation and miRNA activity [24].

5

https://mc04.manuscriptcentral.com/cares 
An example of IncRNA involved in DNA replication and maintenance of telomere stability is TERRA, a transcript containing telomeric UUAGGG repeats able to sequester the single strand DNA-binding protein hnRNPA1 and essential for DNA replication [36; 37] (Figure 1 A). The IncRNA control of nuclear architecture and transcription depends on different biological mechanisms. One of these is the long range DNA looping formation [38], promoting inter-or trans-chromosomal interactions to bring together enhancer/promoter pairs, or different promoters separated by large stretches on the same chromosome, or on different chromosomes [39] (Figure 1 B). Nuclear IncRNAs, interacting with chromatin and chromatin modification complexes or regulating gene expression, generally show low stability, allowing a dynamic gene expression control in response to environmental signals [28]. Furthermore, some of the nuclear sub-compartments are assembled on IncRNAs, such as the nuclear-enriched abundant transcript 1 (NEAT1). NEAT1 has been shown to scaffold nuclear paraspeckles, mammalian-specific ribonucleoprotein bodies regulating mRNA splicing and maturation, through RNA sequestering [40; 41] (Figure $1 \mathrm{C}$ ). IncRNAs belonging to NAT subclass, unlike proteins, can also act in cis or trans to guide epigenetic modifier complexes to targeted sites, by pairing with DNA or mRNA sequences (Figure $1 \mathrm{D}$ ). The cis function consists in the recruitment of protein complexes to their site of transcription, conversely the trans activity leads to the formation of protein complexes by binding and sequestering transcription factors away from their targeted chromosomal regions which are their site of transcription [42].

The IncRNAs transcription can generate a molecular structure that may lead the formation or remodeling of nuclear domains, through the recruitment or sequestration of proteins already present in the nuclear compartment, influencing their interactions [43]. These interchromatin granules are often characterized by specific functions such as pre-mRNA splicing and maturation. Unlike cellular organelles, these domains are not membrane delimited, but they are characterized by the specific interactors forming them in a stable fashion, maintaining the components associated (Figure $1 \mathrm{E}$ ). They often form close to the sites of RNA components involved in transcription, thus functioning as molecular anchors [44]. A well known IncRNAmediated biological event concerning transcription regulation and based on nuclear architecture modification is $X$ chromosome-inactivation (Figure $1 \mathrm{~F}$ ) as well as the imprinting activity of IncRNAs and their role in the fine regulation of epigenetic modifications [24]. By means of IncRNA regulatory function, the transcriptional status of an entire chromosome can be controlled in a regional-, locus- or even allelespecific manner, through the recruitment of chromatin modifiers to the site of transcription. These complexes can create a local chromatin environment that may promote or inhibit the assembling of other regulators [45].

At cytoplasmic level the IncRNAs can control mRNA and protein stability, as well as mRNA transport and localization (Figures $1 \mathrm{G}$ and $\mathrm{H}$ ). The activity of TINCR (terminal differentiation-induced ncRNA) is an example of a IncRNA involved in post-transcriptional regulatory mechanims. TINCR is required during 6 
epidermal differentiation for the induction of specific key mediators. It localizes in the cytoplasm and, through the interaction with Staufen 1 protein (STAU1), promotes the stability of mRNAs containing the TINCR box motif [2]. LncRNAs can also have a role in the regulation of translation through the binding of the sense mRNA and consequent impairment of ribosome entry or arrest of translation between the initiation and elongation steps. In this context lincRNA-p21 was reported to interact with the DDX6 (DEAD box helicase 6) translational repressor in particular conditions, repressing the translation of its mRNA targets [46] (Figures $1 \mathrm{H}$ ). On the contrary, an instance of positive regulation of translation is provided by the antisense Uchl1 IncRNA (UCHL1-AS1), which has been shown to increase the UCHL1 protein level without leading to a change of the mRNA level [47]. UCHL1-AS1 overlaps the first 73 nucleotides of UCHL1 mRNA and contains two embedded repetitive sequences, one of which, SINEB2, is necessary for the induction of protein translation [47]. This repetitive sequence is present in many other IncRNAs from FANTOM3 database, suggesting a potential role of these RNA species in positively regulating translation of target transcripts [48].

LncRNAs were demonstrated to interact also with miRNAs and their target sites thereby modulating miRNA activity [49]. Interestingly, a number of IncRNAs has been reported to act as miRNA sponges, reducing the molecules available to bind their mRNA targets [24]. These RNA cross-interactions suggest the presence in the cell of a ncRNA network where these molecules mutually regulate themselves by sequestering each other temporarily, or by degrading each other through dsRNA formation [21; 50] (Figure $1 \mathrm{I}$ ).

The current knowledge on the IncRNAs mode of action shows how these RNA molecules play important roles at different levels of gene expression regulation, particularly when a fine tuning of a specific gene transcription is necessary to produce a fast response to stimuli of different origin. This regulatory function is consistent with mechanisms leading to a short IncRNA half-life and with a number of IncRNAs that currently seem to be higher than that of protein-coding genes (NONCODE Ev4 ID http://www.noncode.org/analysis.php), providing the nucleus with a very complex RNA-based system aimed at regulating coding-gene expression [15]. A regulatory mechanism based on an RNA-address code may act more rapidly and with a lower energy cost than a system based only on proteins [23]. In fact, IncRNAs do not need to be translated and/or transported into the cytoplasm and their targets are usually localized close to or overlapping with their own genomic loci. In contrast to the model of nuclear domains promoting molecular interactions, the spatial-based control can lead to the separation of the interactors until the appropriate moment. Environmental stresses may have as consequences the retention of specific proteins in the nucleolus, away from their normal site of action, thanks to the expression of specific noncoding RNAs [51]. According to the current knowledge on IncRNA functions, these RNA molecules are part of regulatory mechanisms for a fine control of gene expression able to respond to internal/external environmental changes, to manage complex biological events or developmental programs. 


\section{LnCRNAs IN NEURODEGENERATIVE DISEASES}

Recent data highlight that IncRNAs are important in the development and functioning of the nervous system by both promoting the self-renewal of neural stem cells and neuronal differentiation, and by participating in the control of synaptic plasticity. Although a precise functional role in the nervous system has been attributed only to a few of them so far, IncRNAs have been described to be differentially expressed at specific stages during CNS development [52] or in specific cerebral regions [53].

It is therefore not surprising that misregulation of IncRNAs might play a pathogenetic role in neurodegenerative diseases. This view has been reinforced by the identification of a growing number of IncRNAs that directly regulate the expression of genes associated to neurodegenerative disorders, including Alzheimer's, Parkinson's, Huntington's diseases, Fragile X syndrome and Fragile X tremor/ataxia syndrome as well as spinocerebellar ataxia 7 or, by still unexplored mechanisms, the alternative splicing or mRNA transport/localization, as recently described in Frontotemporal dementia/Amyotrophic lateral sclerosis and spinocerebellar ataxia 8 , respectively (Table 1 ).

In the following paragraphs, we will describe the diverse mechanisms reported for IncRNAs in neurodegenerative diseases and discuss how they could mechanistically be involved in the neurodegenerative processes.

\section{Alzheimer Disease}

Alzheimer disease $(A D)$ is the most common neurodegenerative disease affecting aged population and, etiologically, it is a complex disorder with the majority of cases occurring as sporadic ones and only $10 \%$ showing family history. Genes associated to familial forms are mainly implicated in the processing and maturation of the amyloid precursor protein (APP) into the cleaved $A \beta$ peptides which can form extracellular deposits in affected brains, the senile plaques, when the more amyloidogenic $A \beta 42$ peptide is generated. This process is highly dependent on the correct cleavage of APP by the $\gamma$ and $\beta$ secretase enzymes. The antisense transcript of the $\beta$-secretase encoding gene BACE1 (BACE1-AS) was reported to increase the stability of BACE1 mRNA and to prevent binding of miRNA 485-5p, therefore positively regulating BACE1 protein content and promoting AB42 synthesis (Figure 2) [54]. Expression of BACE1-AS can be induced by different cell stressors, including treatment with $A \beta 42$ itself, which suggests a feedforward mechanism in AD pathogenesis [55]. Interestingly, BACE1-AS expression is elevated in AD patients brains together with the RNA-binding protein HuD which can bind both BACE1 and BACE1-AS transcripts and increase their stability (Figure 2) $[55 ; 56]$. HuD can also bind and stabilize APP mRNA, thereby promoting $A B 42$ peptide formation by increasing APP and BACE1 protein content as well as BACE1-AS IncRNA level [56]. This was observed both in cortical tissue from AD individuals and in transgenic mice over8 
expressing HuD protein. As a therapeutic approach, modulation of BACE1 and BACE1-AS transcripts in APP transgenic mice by transient in vivo silencing was effective in reducing $A \beta$ aggregation [57]. This potential therapeutic strategy targeting BACE1 and BACE1-AS was also confirmed in a human neuroblastoma disease cell model where gene-silencing of BACE1-AS decreased the BACE1-dependent cleavage of APP with a consequent reduction of senile plaque formation [58].

A recent genome-wide search for differentially expressed IncRNAs in post-mortem human AD brains revealed a specific disease-associated signature with both up-regulated and down-regulated IncRNAs, mainly representing intergenic IncRNAs [59]. Although the mode of action of such deregulated IncRNAs is mainly unknown so far, it will be interesting to test whether such IncRNAs may serve as disease-specific biomarkers for AD. The expression of three specific IncRNAs, 17A, NDM29 and 51A was reported to be upregulated in AD affected brains compared to healthy control brain tissues [60-62]. The IncnRNA 17A, embedded in an antisense orientation in the third intron of the human G-protein-coupled receptor 51 (GPR51, also known as GABBR2) gene, was demonstrated to regulate GPR51/GABBR2 pre-mRNA processing and favour the generation of the alternative and unfunctional splicing isoform $B$ of the GABA $B$ receptor (GABAB R2) (Figure 2) [60]. Indeed, the stable expression of $17 A$ in human neuroblastoma cells was shown to increase the synthesis of the GABAB R2 splicing isoform $B$ that is defective of the intramembrane sequence peptide, thus generating non functional receptors unable to transduce GABAB-dependent intracellular signalling. In association to increased levels of the InCRNA $17 A$ and to a defective GABAB signaling, the secretion of the $A \beta$ peptide was found to be induced with an increase in the $A \beta 42 / A \beta 40$ ratio [60]. Similarly, the up-regulation of the IncRNA NDM29 promoted $A \beta$ secretion with an unbalance in the A $442 / A \beta 40$ peptide ratio (Figure 2) [61]. Also the antisense ncRNA 51A, deriving from the first intron of SORL1 gene, a well recognized risk factor for $A D$, was described to promote the alternative splicing of SORL1 and to increase A $\beta$ formation [62]. Interestingly, both 17A and NDM29 ncRNA expression can be induced by inflammatory stimuli, which represent a pathogenic mechanism in $A D$, with the possibility of modulating such effect on $A \beta$ synthesis by using anti-inflammatory drugs [60;61].

The expression of the InCRNA BC200/BCYRN1 (the human orthologue of BC1), which acts as a negative regulator of local protein synthesis at synapses, was reported to be altered in $A D$ patients with opposite results, showing both down-regulation [63] and up-regulation [64] in affected brains. Despite this discrepancy in their observations, which probably reflects the different specific brain areas analyzed by the Authors, $B C 200$ is able to interact with different RNA-binding proteins known to control mRNA translation, including FMRP, PABP1 and SYNCRIP proteins, in post-synaptic dendritic microdomains (Figure 2) [65-67].

\section{Frontotemporal dementia and amyotrophic lateral sclerosis}


Frontotemporal dementia (FTD) is the second important cause of dementia after AD in elderly population and, contrarily to the latter, it affects mainly the frontal and temporal lobes of the brain. Clinically, three different FTD subtypes can be distinguished: behavioral variant FTD, semantic dementia and progressive non-fluent aphasia, each accompanied by specific clinical features. FTD is a hereditary condition in nearly $40 \%$ of cases and several causative genes are associated to the disease, including MAPT, PGRN, C9ORF72 and $V C P$. In the last few years increasing neuropathological and genetic findings have further supported the clinical observations of a disease continuum with motor neuron disease, in particular with amyotrophic lateral sclerosis (ALS). Neuropathological data, in fact, sustain the presence of abnormal cytoplasmic inclusions of the RNA-binding protein (RBP) TDP-43 in affected tissues of a subset of FTD patients (45\%; FTD-TDP) and of nearly all ALS patients. Similarly, another nuclear RBP, FUS/TLS, forms cytoplasmic aggregates in affected tissues of 9\% of FTD patients (FTD-FUS) and in familial ALS forms with mutations in FUS/TLS gene ( 5\%). Genetically, the pathological expansion of the hexanucleotide GGGGCC repeat in the first intron of C9ORF72 gene represents the most frequent cause of both familial and sporadic FTD and ALS cases.

The IncRNAs NEAT1_2 and MALAT1 (NEAT2) were recently identified as RNA targets of TDP-43 by different binding assays both in experimental models and in human brains [68; 69]. NEAT1_2 is essential for paraspeckle assembly [40], whereas MALAT1 localizes at distinct nuclear sub-domains, the speckles, in association to different splicing factors [70]. Interestingly, binding of TDP-43 to these two IncRNAs was reported to be increased in human FTD brains compared to healthy controls [69]. Also FUS/TLS was shown to bind to NEAT1_2 IncRNA although at a distinct site compared to TDP-43 and to associate to a consistent fraction (30\%; 71/234) of all literature annotated IncRNAs [71]. Both TDP-43 and FUS co-localize with the IncRNA NEAT1_2 in the nuclear paraspeckles in experimental cell lines, but NEAT1_2 expression and localization in paraspeckels are increased in spinal motoneurons of sporadic ALS patients at early stages of disease [69]. Moreover, FUS loss-of-function was shown to impair paraspeckle assembly in disease cell models, while FUS-positive aggregates in the cytoplasm associated to FUS mutations induced sequestration of paraspeckle proteins [72].

In a different context, the RBP FUS/TLS was also described to interact with a series of IncRNAs transcribed from the 5' region of CCND1 (Cyclin D1) gene in response to experimentally induced DNA damage [73]. Such IncRNAs-RBP binding determines a specific conformational change of FUS/TLS protein, making it able to bind to the histone acetyltransferases CBP and p300 and, as a consequence, to inhibit their activities as transcriptional co-activators [73].

Therefore in FTD and ALS diseases where the activity of TDP-43 and FUS is impaired affecting RNA metabolism at different levels, also the interaction of these two RBPs with IncRNAs may be defective, representing a novel pathogenetic mechanism to be explored.

10 


\section{Parkinson disease}

Parkinson disease (PD) is mainly a movement disorder, often accompanied by sensory and cognitive deficits or sleep problems, and is characterized by the specific neurodegeneration of the dopaminergic neurons in the substantia nigra. Similarly to AD and ALS, only a minor proportion of cases $(5-10 \%)$ is familial with a wide genetic heterogeneity in both dominant and recessive disease forms. Several causative genes, including Parkin, DJ-1 and PINK1, strongly support mitochondria dysfunction as one important pathogenetic mechanism in PD. PINK1 (PTEN-induced putative kinase 1) is involved in multiple aspects of mitochondria quality control and acts as a sensor of damaged mitochondria. By accumulating on the outer membrane of depolarized mitochondria, PINK1 is able to recruit also Parkin ubiquitin ligase on damaged mitochondria and to target them to degradation through autophagy. In line with a view of regulatory networks controlling target mRNA and protein content through epigenetic mechanisms, an antisense transcript of PINK1 gene (PINK1-AS) was described to have a regulatory function on a short PINK1 splicing isoform (sVPINK1) encoding for the C-terminal region of the PINK1 protein with kinase activity [74]. The ncRNA PINK1-AS specifically and positively regulates the stability of the sVPINK1 transcript, although it is not clear yet the role of this short PINK1 protein isoform and its relevance in PD pathogenesis.

Also the antisense transcript of UCHL1 (ubiquitin carboxy-terminal hydrolase L1), UCHL1-AS1, which is associated to PD both as a risk factor and as a rare causative gene, was recently identified in mice to exert its regulatory function on its target Uchl1 mRNA at translational level [47]. UCHL1 protein is specifically expressed in the brain and in dopaminergic neurons where it is involved in the ubiquitin-proteasome system (UPS) by acting both in tagging proteins for degradation and in recycling ubiquitin molecules from degraded proteins. The IncRNA AS-Uchl1 is mainly localized in the nucleus but, upon rapamycin treatment which inhibits mTOR pathway and CAP-dependent translation, it is induced to translocate into the cytoplasm. As a consequence, an increased association of its target Uchl1 transcript to heavier polysomes and an increased translation of the UCHL1 protein are observed as strictly dependent on AS-Uchl1 binding to its sense Uch/1 mRNA [47]. It is interesting to note that the ability of the IncRNA AS-Uchl1 to positively regulate translation of its sense transcript is due to the presence of the SINEB2 repetitive element $[47 ; 48]$. A recent RNA-seq approach in leukocytes and brain tissues from PD patients and controls revealed deregulation of specific IncRNAs, including the U1 spliceosomal IncRNA which was commonly up-regulated in PD blood and brain [75], suggesting its potential use as a disease biomarker.

\section{Huntington's disease}


Huntington's disease (HD) is an autosomal dominant progressive neurodegenerative disorder caused by a CAG trinucleotide repeat expansion in exon 1 of huntingtin (HTT) gene, which generates a mutant huntingtin protein with an expanded polyglutamine tract at the $\mathrm{N}$-terminus and potential toxic effects [76]. A natural antisense transcript, HTT-AS, was identified at the Huntington's disease repeat locus. The HTT-AS gene contains three exons and gives rise to two alternatively spliced isoforms: HTT-AS_v1, which is composed by exons 1 and 3 and includes the CAG repeat, and HTT-AS_v2, containing only exons 2 and 3 . It was shown that the repeat expansion reduces HTT-AS_v1 expression and, consistently, the levels of HTTAS_v1 are reduced in human HD frontal cortex. Moreover, HTT-AS_v1 is able to negatively regulate HTT expression in a repeat length-dependent manner [77].

A role of $B D N F-A S$, a IncRNA transcribed starting from the brain derived neutrophic factor (BDNF) opposite strand, in the development of HD was also suggested. BDNF levels are known to be strongly downregulated in the brains of HD patients, possibly contributing to the clinical manifestations of the disease [78]. It was recently shown that BDNF-AS knock-down is able to induce BDNF upregulation [79]. In addition, BDNF-AS was demonstrated to inhibit BDNF transcription by recruiting the EZH2 catalitic subunit of the PRC2 silencing complex to the BDNF promoter, with consequent methylation of Lys 27 of histone H3 (H3K27me2/3) [80; 81]. This evidence suggests a potential role of BDNF-AS dysregulation in HD pathogenesis.

Another IncRNA potentially involved in HD is ABHD11-AS1. The mouse ortholog, named Abhd11os, is enriched in the striatum and its expression levels are markedly reduced in different mouse models of HD. Interestingly, Abhd11os overexpression is neuroprotective against an N-terminal fragment of the mutant huntingtin, whereas Abhd11os knockdown is protoxic, indicating that the loss Abhd11os likely contributes to striatal vulnerability in $\mathrm{HD}$ [82].

Many other IncRNAs have been found to be dysregulated in HD and might play a significant role in HD neurodegeneration. Among them, the neural human accelerated region 1 (HAR1) IncRNA was shown to be repressed by REST (which is aberrantly localized to the nucleus in HD neurons) and to display significantly lower levels in the striatum of HD patients [83]. Another IncRNA found to be deregulated in HD is the TUNA ( Tcl1 upstream neuron associated) lincRNA, which is involved in pluripotency and neural differentiation of embryonic stem cells. The expression of TUNA in the striatum of HD patients was found to be associated with pathological disease severity, decreasing significantly as the disease grade increased [84]. Moreover, the analysis of microarray data revealed that TUG1, LINC000341, RPS20P22, NEAT1 IncRNAs are upregulated in HD brains, while MEG3, DGCR5, LINC000342 are downregulated [85]. It is worth noting that among these genes there are REST and p53 targets, and some of them are also known to interact with the PRC2 complex. Interestingly, the NEAT1 IncRNA was also proposed to be involved in ALS pathogenesis (see above).

12 


\section{Fragile $X$ syndrome and Fragile $X$ tremor/ataxia syndrome}

Fragile $\mathrm{X}$ syndrome (FXS) is a genetic neurodevelopmental disorder characterized by moderate to severe intellectual deficit, macroorchidism and distinct physical features, which is caused by the expansion beyond 200 repeats of a CGG trinucleotide repeat in the $5^{\prime}$-untranslated region (5'-UTR) of the Fragile X mental retardation 1 (FMR1) gene [86]. This repeat expansion, called 'full mutation', causes FMR1 upstream region to be abnormally methylated, resulting in FMR1 transcriptional silencing and decreased protein levels in the brain. Fragile $X$ tremor/ataxia syndrome (FXTAS) is a neurodegenerative disease whose pathogenesis is distinct from that of fragile $X$ syndrome. FXTAS is caused by the expansion of the same CGG repeat in the FMR1 gene, but, differently from FXS, the expanded repeat ranges from 55 to 200 units in size (the socalled 'premutation'), resulting in a toxic gain-of-function of FMR1 RNA [87].

Different IncRNAs were recently discovered at the FMR1 locus which display altered expression in FXS and FXTAS. FMR1-AS1 (FMR1 antisense RNA 1), also known as ASFMR1 or FMR4, is a primate-specific IncRNA overlapping the CGG repeat region, sharing the promoter with FMR1 and transcribed in the opposite direction [88; 89]. The repeat expansion seems to affect transcription in both directions as, similarly to FMR1, the expression of FMR1-AS1 was also found to be upregulated in FXTAS patients carrying the premutation and silenced in full mutated FXS patients. Interestingly, the FMR1-AS1 premutated transcript exhibits a specific splicing isoform which is absent in the case of normal or full mutated alleles [88]. FMR1AS1 was not shown to have a regulatory activity on FMR1 expression, but FMR1-AS1 knockdown enhanced apoptosis while its overexpression increased cell proliferation, suggesting an anti-apoptotic function and a possible role in protection of neurons from death [89]. Furthermore, in differentiating human neural precursor cells (hNPCS), FMR1-AS1 expression is developmentally regulated in opposition to expression of both FMR1 and MBD4 (methyl-CpG-binding domain protein 4), a FMR1-AS1-responsive gene, indicating a likely gene-regulatory function of this IncRNA during normal development [90]. Very recently, FMR1-AS1 was also found to be a chromatin-associated transcript and it was shown to alter the chromatin state and the expression of several hundred genes in trans. Among these genes, there was an enrichment for those involved in neural development and cellular proliferation. Indeed, it was further demonstrated that FMR1AS1 may promote cellular proliferation of hNPCs [91]. It was also proposed that altered FMR1-AS1 expression might contribute to some clinical aspects of FXS/FXTAS [89].

In addition, Pastori and colleagues [92] identified two further IncRNAs mapping to the FMR1 locus: FMR5 and FMR6. FMR5 is a sense transcript localized upstream of the FMR1 promoter and found to be expressed at low levels in both FXS/FXTAS patients and healthy individuals' brains, without significantly differences between full mutation, premutation and control samples. FMR6 is an antisense transcript overlapping the $3^{\prime}$ region of FMR1, which is specifically silenced in both FXS and FXTAS patients. Since these two IncRNAs 13 
were expressed in peripheral blood leukocytes, they were proposed as useful biomarkers for FXS/FXTAS early detection and therapeutic intervention [92].

\section{Spinocerebellar ataxia}

Spinocerebellar ataxias (SCAs) are a complex group of clinically and genetically heterogeneous neurodegenerative diseases characterized by progressive cerebellar ataxia in association with a broad spectrum of neurological and other clinical conditions.

Spinocerebellar ataxia type 8 (SCA8), a slowly progressive ataxia, is caused by an expanded CTG/CAG trinucleotide repeat (usually 80-250 units) on chromosome 13q21. Two genes transcribed in opposite directions encompass the repeat: ataxin 8 (ATXN8), encoding a polyglutamine protein in the CAG direction, and ataxin 8 opposite strand (ATXN8OS), whose transcription produces a noncoding RNA with a CUG expansion [93]. The ATXN8OS IncRNA containing the CUG repeat expansion was demonstrated to accumulate in ribonuclear inclusions along with the RBP MBNL1, and to cause splicing changes and increased expression of the GABA-A transporter 4 (GAT4/Gabt4), suggesting the involvement of toxic gainof-function effects of the expanded-repeat ATXN8OS transcript in SCA8 pathogenesis [94]. Moreover, it was shown that the expression of human ATXN8OS in Drosophila induces late-onset neurodegeneration of the retina [95]. This effect was seen following the overexpression of both the wild-type and the repeatexpanded IncRNA, but it was proposed that the CUG expansion could alter the binding of ATXN8OS to RBPs. In particular, ATXN8OS was demonstrated to interact with Staufen, an RBP conserved in Drosophila and humans that mediates mRNA localization and transport in the nervous system. It is interesting to note that the ATXN8OS binding domain maps to the region which is expanded in SCA8 patients, suggesting that the interaction with Staufen could be compromised by the CUG repeat expansion, leading to disease [95].

Spinocerebellar ataxia type 7 (SCA7) is a neurodegenerative disorder due to a CAG trinucleotide/polyglutamine repeat expansion (usually 36 or more repeats) in the ataxin 7 (ATXN7) gene [96]. Larger CAG-repeat expansions are associated with an earlier disease onset and a more severe disease progress. A InCRNA, SCAANT1 (SCA7/ATXN7 antisense RNA 1), was identified in the ataxin-7 promoter region which is transcribed antisense to the ATXN7 gene starting from an alternative promoter. Loss of SCAANT1 was shown to derepress ataxin-7 sense transcription from the alternative promoter and was accompanied by chromatin remodeling. On the contrary, upregulation in cis of SCAANT1 transcription caused down-modulation of ATXN7 and was accompanied by post-translational modification of histones [97]. These data demonstrated the involvement of the SCAANT1 antisense IncRNA in the regulation of ATXN7 expression, also indicating a likely contribution of IncRNA-mediated altered epigenetic regulation to SCA7 disease pathogenesis. Another InCRNA, ATXN7L3B (also known as InC-SCA7), was shown to interact directly with ATXN7 mRNA. The nature of this interaction is likely to be regulatory, since mutations in 14 
ATXN7 disrupt the interaction and result in a neuron-specific increase in ATXN7 expression, predominantly in the SCA7 disease-relevant tissues, the retina and cerebellum, contributing to the selective neurodegeneration observed in SCA7 [98].

\section{CONCLUSIONS AND FUTURE DIRECTIONS}

The role of IncRNAs in the pathogenesis of neurodegenerative disorders is only beginning to be explored, but promises to open a new scenario for the setting up of innovative therapies for diseases for which no effective cure is available.

The great variety of IncRNA mechanisms of action and the relatively limited number of studies on IncRNAs in specific neurodegenerative diseases make it difficult to assemble a precise and conclusive picture of their involvement in these disorders. This notwithstanding, some recurrent pathomechanisms are clearly emerging from the literature data. Among them, the most straightforward is the dysregulation of IncRNAs which can in turn affect the expression of genes involved in the neurodegenerative process (e.g. BACE1), acting at different levels (chromatin structure, transcription, mRNA stability, translational efficiency, miRNA binding). This is usually the case, for instance, of many antisense transcripts transcribed from the same locus of the sense gene. Another group of IncRNAs deserving particular attention is composed by those IncRNAs which are able to interact with components of the epigenetic machinery, since their deregulation potentially alters the chromatin state and the expression of several genes, affecting multiple pathways involved in neurodegeneration. Another property of IncRNAs which can be relevant in triggering the neurodegenerative events is their ability to interact with RNA-binding proteins (RBPs) because, again, their dysregulation may impact the processing, stability, translation and localization of many different target transcripts. In some cases, the accumulation of a given IncRNA may have a toxic effect, as in the case of repeat expansion diseases. In other cases, our knowledge is limited to an evidence of IncRNA expression changes in the brains of affected patients compared to the healthy individuals and functional studies aimed at shedding light on their involvement in the neurodegenerative diseases are missing.

The elucidation of the IncRNA-mediated mechanisms of action is fundamental to better understand their role in brain functioning and their implication in the occurrence of neurodegenerative conditions. For this purpose, an effective strategy will be to study the effect of knocking-out or knocking-down specific IncRNAs in suitable model organisms and cell lines. Moreover, reports on the role of IncRNAs in cancers and malignant diseases of the CNS such as glioblastoma which are both numerous, and age-related and neurodegenerative in nature [8], may help shed light on the mechanisms of IncRNAs in neurodegenerative diseases. The latest transcriptome sequencing technologies, along with the development of suitable bioinformatic tools for identifying new potentially functional IncRNAs, will allow to expand the repertoire of known IncRNAs and to identify those which are dysregulated during the neurodegenerative processes. In 15 
addition, as our knowledge on the role of IncRNAs in the neurodegenerative disorders progresses, other evidence of dysregulated IncRNAs shared by different pathologies could also emerge, as in the case of NEAT1, uncovering common IncRNA-mediated pathomechanisms.

Importantly, the identification of IncRNA expression profiles robustly associated to the disease condition will prompt the use of IncRNAs as diagnostic and predictive biomarkers, especially if abnormal IncRNA expression patterns can be detected in blood and/or CSF of patients. In support of this perspective, the use of IncRNAs as diagnostic and prognostic markers is already successfully exploited in the field of oncology [8]. Moreover, a deeper understanding of the role of IncRNAs in neurodegenerative disorders will ultimately enable the development of innovative therapeutic strategies with IncRNAs as drug targets. A potential therapeutic intervention based on the reduction of the UBE3A antisense transcript (UBE3A-ATS) IncRNA using antisense oligonucleotides has been recently proposed for the treatment of patients affected by Angelman syndrome [99] and analogous oligonucleotide-mediated therapeutic strategies are also being developed by biotechnology companies for a wide range of disorders. Therefore we are confident that the experience gained in the above clinical fields will have also promising applications in the area of neurodegenerative diseases. In example, the targeted down-regulation of BACE1-AS, 17A, NDM29 and 51A IncRNAs by specific antisense oligonucleotides could represent a potential therapeutic approach to reduce $A \beta$ production in Alzheimer's disease as it already was shown to be effective in $A D$ animal and cell models $[57 ; 58 ; 60 ; 61]$. Another conceivable strategy may consist in the pharmacological modulation of IncRNAs to modify consequently the expression of known target genes involved in neurodegeneration.

In conclusion, IncRNAs can be considered a great promise for one of the major challenges of the last decades, early diagnosis and cure of neurodegenerative diseases that are having an increasing social impact with the lengthening of human lifespan.

\section{CONFLICT OF INTEREST:}

The authors declare that they have no conflict of interest. 


\section{FIGURE LEGENDS}

Figure 1: Regulatory mechanisms mediated by IncRNAs in the nucleus and in the cytoplasm

Nuclear functions of IncRNAs: A. The IncRNA TERRA maintains telomere stability during DNA replication; B. IncRNAs promote inter- or trans-chromosomal interactions regulating transcription of target loci; $\mathrm{C}$. IncRNAs are able to scaffold nuclear paraspeckles, participating in the regulation of mRNA splicing and maturation; D. IncRNAs can also act in cis or trans to guide epigenetic modifier complexes to targeted sites, by pairing with DNA or mRNA sequences; $E$. IncRNAs can generate inter-chromatin granules involved in premRNA splicing and maturation; F. IncRNAs have a role in X-chromosome inactivation by nuclear architecture modification. Cytoplasmatic functions of IncRNAs: G. IncRNAs can positively or negatively regulate target mRNA stability; $\mathrm{H}$. IncRNAs can regulate protein levels by controlling their translation and stability; I. IncRNAs can interact with miRNAs acting as molecular sponge to modulate their activity .

Figure 2: Dysregulated IncRNAs and affected pathways in the pathogenesis of Alzheimer's disease. The BACE1-AS transcript increases the stability of BACE1 mRNA and prevents the binding of miR-485-5p, positively regulating $B A C E 1$ and promoting $A \beta 42$ formation. BACE1-AS expression levels are elevated in $A D$ and can be induced by A 342 itself, creating a feed-forward mechanism. Moreover, the RNA-binding protein HuD can bind both BACE1 and BACE1-AS transcripts, increasing their stability. The IncnRNA 17A, which is embedded in an antisense orientation within the GABBR2 gene, is upregulated in $A D$ and favours the synthesis of the GABBR2 receptor splicing isoform $B$ that is defective in transducing the GABAB-dependent intracellular signalling. The up-regulation of $17 A$, as well as of the IncRNA NDM29, promotes $A \beta$ secretion with an increase in the $A \beta 42 / A \beta 40$ peptide ratio. The antisense IncRNA 51A, located in the first intron of SORL1 gene, promotes the alternative splicing of SORL1 and increases $A \beta$ formation. Finally, the expression of the IncRNA $B C 200$, which acts as a regulator of local protein synthesis at synapses, can be both down- or up-regulated in AD brains. $B C 200$ is able to interact with different RNA-binding proteins known to control mRNA translation in post-synaptic dendritic microdomains. The vertical arrows shown on the left of InCRNAs BACE1-AS, NDM29, 17A and BC200 indicate up- or down-regulation in AD.

$A B=$ amyloid-beta peptide; $A P P=$ amyloid precursor protein; $B A C E 1=$ beta-site $A P P$-cleaving enzyme $1 ;$ BACE1-AS= BACE1 antisense RNA; BC200= brain cytoplasmic RNA of 200 nucleotides; GABBR2= gammaaminobutyric acid (GABA) B receptor 2; HuD= Hu-antigen D/ELAV like protein 4; NDM29= neuroblastoma differentiation marker 29; RBPs= RNA-binding proteins; SORL1= sortilin-related receptor, L(DLR class) $A$ repeats containing.

17 


\section{REFERENCES}

[1] Iyengar BR, Choudhary A, Sarangdhar MA, Venkatesh KV, Gadgil CJ, Pillai B. Non-coding RNA interact to regulate neuronal development and function. Front Cell Neurosci 8: 47.(2014).

[2] Kretz M, Siprashvili Z, Chu C, Webster DE, Zehnder A, Qu K, et al. Control of somatic tissue differentiation by the long non-coding RNA TINCR. Nature 493(7431): 231-5.(2013).

[3] Ying L, Huang Y, Chen H, Wang Y, Xia L, Chen Y, et al. Downregulated MEG3 activates autophagy and increases cell proliferation in bladder cancer. Mol Biosyst 9(3): 407-11.(2013).

[4] Wang P, Xue Y, Han Y, Lin L, Wu C, Xu S, et al. The STAT3-binding long noncoding RNA Inc-DC controls human dendritic cell differentiation. Science 344(6181): 310-3.(2014).

[5] Tan L, Yu JT, Hu N, Tan L. Non-coding RNAs in Alzheimer's disease. Mol Neurobiol 47(1): 382-93.(2013).

[6] Gstir R, Schafferer S, Scheideler M, Misslinger M, Griehl M, Daschil N, et al. Generation of a neurospecific microarray reveals novel differentially expressed noncoding RNAs in mouse models for neurodegenerative diseases. RNA 20(12): 1929-43.(2014).

[7] Wu GC, Pan HF, Leng RX, Wang DG, Li XP, Li XM, et al. Emerging role of long noncoding RNAs in autoimmune diseases. Autoimmun Rev 14(9): 798-805.(2015).

[8] Li Y, Wang X. Role of long noncoding RNAs in malignant disease (Review). Mol Med Rep 13(2): 14639.(2016).

[9] Rinn JL, Chang HY. Genome regulation by long noncoding RNAs. Annu Rev Biochem 81: 145-66.(2012).

[10] Cabili MN, Trapnell C, Goff L, Koziol M, Tazon-Vega B, Regev A, et al. Integrative annotation of human large intergenic noncoding RNAs reveals global properties and specific subclasses. Genes Dev 25(18): 191527.(2011).

[11] Djebali S, Davis CA, Merkel A, Dobin A, Lassmann T, Mortazavi A, et al. Landscape of transcription in human cells. Nature 489(7414): 101-8.(2012).

[12] Ravasi T, Suzuki H, Pang KC, Katayama S, Furuno M, Okunishi R, et al. Experimental validation of the regulated expression of large numbers of non-coding RNAs from the mouse genome. Genome Res 16(1): 11-9.(2006).

[13] Zhang B, Gunawardane L, Niazi F, Jahanbani F, Chen X, Valadkhan S. A novel RNA motif mediates the strict nuclear localization of a long noncoding RNA. Mol Cell Biol 34(12): 2318-29.(2014).

[14] Salta E, De Strooper B. Non-coding RNAs with essential roles in neurodegenerative disorders. Lancet Neurol 11(2): 189-200.(2012).

[15] Derrien T, Johnson R, Bussotti G, Tanzer A, Djebali S, Tilgner H, et al. The GENCODE v7 catalog of human long noncoding RNAs: analysis of their gene structure, evolution, and expression. Genome Res 22(9): 1775-89.(2012).

[16] Tilgner H, Knowles DG, Johnson R, Davis CA, Chakrabortty S, Djebali S, et al. Deep sequencing of subcellular RNA fractions shows splicing to be predominantly co-transcriptional in the human genome but inefficient for IncRNAs. Genome Res 22(9): 1616-25.(2012).

[17] Duret L, Chureau C, Samain S, Weissenbach J, Avner P. The Xist RNA gene evolved in eutherians by pseudogenization of a protein-coding gene. Science 312(5780): 1653-5.(2006).

[18] Banfai B, Jia H, Khatun J, Wood E, Risk B, Gundling WE, Jr., et al. Long noncoding RNAs are rarely translated in two human cell lines. Genome Res 22(9): 1646-57.(2012).

[19] Ingolia NT, Lareau LF, Weissman JS. Ribosome profiling of mouse embryonic stem cells reveals the complexity and dynamics of mammalian proteomes. Cell 147(4): 789-802.(2011).

[20] Bazzini AA, Johnstone TG, Christiano R, Mackowiak SD, Obermayer B, Fleming ES, et al. Identification of small ORFs in vertebrates using ribosome footprinting and evolutionary conservation. EMBO J 33(9): 98193.(2014).

[21] Memczak S, Jens M, Elefsinioti A, Torti F, Krueger J, Rybak A, et al. Circular RNAs are a large class of animal RNAs with regulatory potency. Nature 495(7441): 333-8.(2013).

[22] Gibb EA, Brown CJ, Lam WL. The functional role of long non-coding RNA in human carcinomas. Mol Cancer 10: 38.(2011). 
[23] Batista PJ, Chang HY. Long noncoding RNAs: cellular address codes in development and disease. Cell 152(6): 1298-307.(2013).

[24] Khorkova O, Hsiao J, Wahlestedt C. Basic biology and therapeutic implications of IncRNA. Adv Drug Deliv Rev 87: 15-24.(2015).

[25] Guttman M, Amit I, Garber M, French C, Lin MF, Feldser D, et al. Chromatin signature reveals over a thousand highly conserved large non-coding RNAs in mammals. Nature 458(7235): 223-7.(2009).

[26] Tordonato C, Di Fiore PP, Nicassio F. The role of non-coding RNAs in the regulation of stem cells and progenitors in the normal mammary gland and in breast tumors. Front Genet 6: 72.(2015).

[27] Maekawa S, Imamachi N, Irie T, Tani H, Matsumoto K, Mizutani R, et al. Analysis of RNA decay factor mediated RNA stability contributions on RNA abundance. BMC Genomics 16: 154.(2015).

[28] Clark MB, Johnston RL, Inostroza-Ponta M, Fox AH, Fortini E, Moscato P, et al. Genome-wide analysis of long noncoding RNA stability. Genome Res 22(5): 885-98.(2012).

[29] Ulitsky I, Bartel DP. lincRNAs: genomics, evolution, and mechanisms. Cell 154(1): 26-46.(2013).

[30] Tani H, Mizutani R, Salam KA, Tano K, ljiri K, Wakamatsu A, et al. Genome-wide determination of RNA stability reveals hundreds of short-lived noncoding transcripts in mammals. Genome Res 22(5): 94756.(2012).

[31] Wang L, Zhou D, Tu J, Wang Y, Lu Z. Exploring the stability of long intergenic non-coding RNA in K562 cells by comparative studies of RNA-Seq datasets. Biol Direct 9: 15.(2014).

[32] Yoon JH, Kim J, Gorospe M. Long noncoding RNA turnover. Biochimie 117: 15-21.(2015).

[33] Ponjavic J, Ponting CP, Lunter G. Functionality or transcriptional noise? Evidence for selection within long noncoding RNAs. Genome Res 17(5): 556-65.(2007).

[34] Ponting CP, Oliver PL, Reik W. Evolution and functions of long noncoding RNAs. Cell 136(4): 62941.(2009).

[35] Orom UA, Derrien T, Beringer M, Gumireddy K, Gardini A, Bussotti G, et al. Long noncoding RNAs with enhancer-like function in human cells. Cell 143(1): 46-58.(2010).

[36] Cusanelli E, Romero CA, Chartrand P. Telomeric noncoding RNA TERRA is induced by telomere shortening to nucleate telomerase molecules at short telomeres. Mol Cell 51(6): 780-91.(2013).

[37] Webb CJ, Wu Y, Zakian VA. DNA repair at telomeres: keeping the ends intact. Cold Spring Harb Perspect Biol 5(6)2013).

[38] Shibayama Y, Fanucchi S, Magagula L, Mhlanga MM. IncRNA and gene looping: what's the connection? Transcription 5(3): e28658.(2014).

[39] Fanucchi S, Shibayama Y, Burd S, Weinberg MS, Mhlanga MM. Chromosomal contact permits transcription between coregulated genes. Cell 155(3): 606-20.(2013).

[40] Clemson CM, Hutchinson JN, Sara SA, Ensminger AW, Fox AH, Chess A, et al. An architectural role for a nuclear noncoding RNA: NEAT1 RNA is essential for the structure of paraspeckles. Mol Cell 33(6): 71726.(2009).

[41] Mao YS, Sunwoo H, Zhang B, Spector DL. Direct visualization of the co-transcriptional assembly of a nuclear body by noncoding RNAs. Nat Cell Biol 13(1): 95-101.(2011).

[42] Wang KC, Chang HY. Molecular mechanisms of long noncoding RNAs. Mol Cell 43(6): 904-14.(2011).

[43] Lee JT. Lessons from X-chromosome inactivation: long ncRNA as guides and tethers to the epigenome. Genes Dev 23(16): 1831-42.(2009).

[44] Dundr M, Misteli T. Biogenesis of nuclear bodies. Cold Spring Harb Perspect Biol 2(12): a000711.(2010). [45] Froberg JE, Yang L, Lee JT. Guided by RNAs: X-inactivation as a model for IncRNA function. J Mol Biol 425(19): 3698-706.(2013).

[46] Yoon JH, Abdelmohsen K, Srikantan S, Yang X, Martindale JL, De S, et al. LincRNA-p21 suppresses target mRNA translation. Mol Cell 47(4): 648-55.(2012).

[47] Carrieri C, Cimatti L, Biagioli M, Beugnet A, Zucchelli S, Fedele S, et al. Long non-coding antisense RNA controls Uchl1 translation through an embedded SINEB2 repeat. Nature 491(7424): 454-7.(2012).

[48] Zucchelli S, Fasolo F, Russo R, Cimatti L, Patrucco L, Takahashi H, et al. SINEUPs are modular antisense long non-coding RNAs that increase synthesis of target proteins in cells. Front Cell Neurosci 9: 174.(2015). 
[49] Jalali S, Bhartiya D, Lalwani MK, Sivasubbu S, Scaria V. Systematic transcriptome wide analysis of IncRNA-miRNA interactions. PLoS One 8(2): e53823.(2013).

[50] Hansen TB, Jensen TI, Clausen BH, Bramsen JB, Finsen B, Damgaard CK, et al. Natural RNA circles function as efficient microRNA sponges. Nature 495(7441): 384-8.(2013).

[51] Audas TE, Jacob MD, Lee S. Immobilization of proteins in the nucleolus by ribosomal intergenic spacer noncoding RNA. Mol Cell 45(2): 147-57.(2012).

[52] Ng SY, Johnson R, Stanton LW. Human long non-coding RNAs promote pluripotency and neuronal differentiation by association with chromatin modifiers and transcription factors. EMBO J 31(3): 52233.(2012).

[53] Mercer TR, Dinger ME, Sunkin SM, Mehler MF, Mattick JS. Specific expression of long noncoding RNAs in the mouse brain. Proc Natl Acad Sci U S A 105(2): 716-21.(2008).

[54] Faghihi MA, Zhang M, Huang J, Modarresi F, Van der Brug MP, Nalls MA, et al. Evidence for natural antisense transcript-mediated inhibition of microRNA function. Genome Biol 11(5): R56.(2010).

[55] Faghihi MA, Modarresi F, Khalil AM, Wood DE, Sahagan BG, Morgan TE, et al. Expression of a noncoding RNA is elevated in Alzheimer's disease and drives rapid feed-forward regulation of betasecretase. Nat Med 14(7): 723-30.(2008).

[56] Kang MJ, Abdelmohsen K, Hutchison ER, Mitchell SJ, Grammatikakis I, Guo R, et al. HuD regulates coding and noncoding RNA to induce APP-->Abeta processing. Cell Rep 7(5): 1401-9.(2014).

[57] Modarresi F, Faghihi MA, Patel NS, Sahagan BG, Wahlestedt C, Lopez-Toledano MA. Knockdown of BACE1-AS Nonprotein-Coding Transcript Modulates Beta-Amyloid-Related Hippocampal Neurogenesis. Int J Alzheimers Dis 2011: 929042.(2011).

[58] Liu T, Huang Y, Chen J, Chi H, Yu Z, Wang J, et al. Attenuated ability of BACE1 to cleave the amyloid precursor protein via silencing long noncoding RNA BACE1AS expression. Mol Med Rep 10(3): 127581.(2014).

[59] Zhou X, Xu J. Identification of Alzheimer's disease-associated long noncoding RNAs. Neurobiol Aging 36(11): 2925-31.(2015).

[60] Massone S, Vassallo I, Fiorino G, Castelnuovo M, Barbieri F, Borghi R, et al. 17A, a novel non-coding RNA, regulates GABA $B$ alternative splicing and signaling in response to inflammatory stimuli and in Alzheimer disease. Neurobiol Dis 41(2): 308-17.(2011).

[61] Massone S, Ciarlo E, Vella S, Nizzari M, Florio T, Russo C, et al. NDM29, a RNA polymerase IIIdependent non coding RNA, promotes amyloidogenic processing of APP and amyloid beta secretion. Biochim Biophys Acta 1823(7): 1170-7.(2012).

[62] Ciarlo E, Massone S, Penna I, Nizzari M, Gigoni A, Dieci G, et al. An intronic ncRNA-dependent regulation of SORL1 expression affecting Abeta formation is upregulated in post-mortem Alzheimer's disease brain samples. Dis Model Mech 6(2): 424-33.(2013).

[63] Lukiw WJ, Handley P, Wong L, Crapper McLachlan DR. BC200 RNA in normal human neocortex, nonAlzheimer dementia (NAD), and senile dementia of the Alzheimer type (AD). Neurochem Res 17(6): 5917.(1992).

[64] Mus E, Hof PR, Tiedge H. Dendritic BC200 RNA in aging and in Alzheimer's disease. Proc Natl Acad Sci U S A 104(25): 10679-84.(2007).

[65] Muddashetty R, Khanam T, Kondrashov A, Bundman M, lacoangeli A, Kremerskothen J, et al. Poly(A)binding protein is associated with neuronal $\mathrm{BC} 1$ and $\mathrm{BC} 200$ ribonucleoprotein particles. J Mol Biol 321(3): 433-45.(2002).

[66] Zalfa F, Adinolfi S, Napoli I, Kuhn-Holsken E, Urlaub H, Achsel T, et al. Fragile X mental retardation protein (FMRP) binds specifically to the brain cytoplasmic RNAs BC1/BC200 via a novel RNA-binding motif. J Biol Chem 280(39): 33403-10.(2005).

[67] Duning K, Buck F, Barnekow A, Kremerskothen J. SYNCRIP, a component of dendritically localized mRNPs, binds to the translation regulator BC200 RNA. J Neurochem 105(2): 351-9.(2008).

[68] Tollervey JR, Curk T, Rogelj B, Briese M, Cereda M, Kayikci M, et al. Characterizing the RNA targets and position-dependent splicing regulation by TDP-43. Nat Neurosci 14(4): 452-8.(2011). 
[69] Nishimoto $Y$, Nakagawa S, Hirose T, Okano HJ, Takao M, Shibata S, et al. The long non-coding RNA nuclear-enriched abundant transcript 1_2 induces paraspeckle formation in the motor neuron during the early phase of amyotrophic lateral sclerosis. Mol Brain 6: 31.(2013).

[70] Tripathi V, Ellis JD, Shen Z, Song DY, Pan Q, Watt AT, et al. The nuclear-retained noncoding RNA MALAT1 regulates alternative splicing by modulating SR splicing factor phosphorylation. Mol Cell 39(6): 925-38.(2010).

[71] Lagier-Tourenne C, Polymenidou M, Hutt KR, Vu AQ, Baughn M, Huelga SC, et al. Divergent roles of ALS-linked proteins FUS/TLS and TDP-43 intersect in processing long pre-mRNAs. Nat Neurosci 15(11): 1488-97.(2012).

[72] Shelkovnikova TA, Robinson HK, Connor-Robson N, Buchman VL. Recruitment into stress granules prevents irreversible aggregation of FUS protein mislocalized to the cytoplasm. Cell Cycle 12(19): 3194202.(2013).

[73] Wang X, Arai S, Song X, Reichart D, Du K, Pascual G, et al. Induced ncRNAs allosterically modify RNAbinding proteins in cis to inhibit transcription. Nature 454(7200): 126-30.(2008).

[74] Scheele C, Petrovic N, Faghihi MA, Lassmann T, Fredriksson K, Rooyackers O, et al. The human PINK1 locus is regulated in vivo by a non-coding natural antisense RNA during modulation of mitochondrial function. BMC Genomics 8: 74.(2007).

[75] Soreq L, Guffanti A, Salomonis N, Simchovitz A, Israel Z, Bergman H, et al. Long non-coding RNA and alternative splicing modulations in Parkinson's leukocytes identified by RNA sequencing. PLoS Comput Biol 10(3): e1003517.(2014).

[76] Walker FO. Huntington's disease. Lancet 369(9557): 218-28.(2007).

[77] Chung DW, Rudnicki DD, Yu L, Margolis RL. A natural antisense transcript at the Huntington's disease repeat locus regulates HTT expression. Human molecular genetics 20(17): 3467-77.(2011).

[78] Zuccato C, Cattaneo E. Role of brain-derived neurotrophic factor in Huntington's disease. Progress in neurobiology 81(5-6): 294-330.(2007).

[79] Modarresi F, Faghihi MA, Lopez-Toledano MA, Fatemi RP, Magistri M, Brothers SP, et al. Inhibition of natural antisense transcripts in vivo results in gene-specific transcriptional upregulation. Nature biotechnology 30(5): 453-9.(2012).

[80] Czermin B, Melfi R, McCabe D, Seitz V, Imhof A, Pirrotta V. Drosophila enhancer of Zeste/ESC complexes have a histone H3 methyltransferase activity that marks chromosomal Polycomb sites. Cell 111(2): 185-96.(2002).

[81] Vashishtha M, Ng CW, Yildirim F, Gipson TA, Kratter IH, Bodai L, et al. Targeting H3K4 trimethylation in Huntington disease. Proc Natl Acad Sci U S A 110(32): E3027-36.(2013).

[82] Francelle L, Galvan L, Gaillard MC, Petit F, Bernay B, Guillermier M, et al. Striatal long noncoding RNA Abhd11os is neuroprotective against an $\mathrm{N}$-terminal fragment of mutant huntingtin in vivo. Neurobiol Aging 36(3): 1601 e7-16.(2015).

[83] Johnson R, Richter N, Jauch R, Gaughwin PM, Zuccato C, Cattaneo E, et al. Human accelerated region 1 noncoding RNA is repressed by REST in Huntington's disease. Physiological genomics 41(3): 269-74.(2010).

[84] Lin N, Chang KY, Li Z, Gates K, Rana ZA, Dang J, et al. An evolutionarily conserved long noncoding RNA TUNA controls pluripotency and neural lineage commitment. Mol Cell 53(6): 1005-19.(2014).

[85] Johnson R. Long non-coding RNAs in Huntington's disease neurodegeneration. Neurobiol Dis 46(2): 245-54.(2012).

[86] D'Hulst C, Kooy RF. Fragile X syndrome: from molecular genetics to therapy. Journal of medical genetics 46(9): 577-84.(2009).

[87] Amiri K, Hagerman RJ, Hagerman PJ. Fragile X-associated tremor/ataxia syndrome: an aging face of the fragile $X$ gene. Archives of neurology 65(1): 19-25.(2008).

[88] Ladd PD, Smith LE, Rabaia NA, Moore JM, Georges SA, Hansen RS, et al. An antisense transcript spanning the CGG repeat region of FMR1 is upregulated in premutation carriers but silenced in full mutation individuals. Human molecular genetics 16(24): 3174-87.(2007). 
[89] Khalil AM, Faghihi MA, Modarresi F, Brothers SP, Wahlestedt C. A novel RNA transcript with antiapoptotic function is silenced in fragile $X$ syndrome. PLoS One 3(1): e1486.(2008).

[90] Peschansky VJ, Pastori C, Zeier Z, Motti D, Wentzel K, Velmeshev D, et al. Changes in expression of the long non-coding RNA FMR4 associate with altered gene expression during differentiation of human neural precursor cells. Front Genet 6: 263.(2015).

[91] Peschansky VJ, Pastori C, Zeier Z, Wentzel K, Velmeshev D, Magistri M, et al. The long non-coding RNA FMR4 promotes proliferation of human neural precursor cells and epigenetic regulation of gene expression in trans. Mol Cell Neurosci2016).

[92] Pastori C, Peschansky VJ, Barbouth D, Mehta A, Silva JP, Wahlestedt C. Comprehensive analysis of the transcriptional landscape of the human FMR1 gene reveals two new long noncoding RNAs differentially expressed in Fragile $X$ syndrome and Fragile $X$-associated tremor/ataxia syndrome. Human genetics 133(1): 59-67.(2014).

[93] Moseley ML, Zu T, Ikeda Y, Gao W, Mosemiller AK, Daughters RS, et al. Bidirectional expression of CUG and CAG expansion transcripts and intranuclear polyglutamine inclusions in spinocerebellar ataxia type 8 . Nature genetics 38(7): 758-69.(2006).

[94] Daughters RS, Tuttle DL, Gao W, Ikeda Y, Moseley ML, Ebner TJ, et al. RNA gain-of-function in spinocerebellar ataxia type 8. PLoS genetics 5(8): e1000600.(2009).

[95] Mutsuddi M, Marshall CM, Benzow KA, Koob MD, Rebay I. The spinocerebellar ataxia 8 noncoding RNA causes neurodegeneration and associates with staufen in Drosophila. Current biology : CB 14(4): 3028.(2004).

[96] David G, Abbas N, Stevanin G, Durr A, Yvert G, Cancel G, et al. Cloning of the SCA7 gene reveals a highly unstable CAG repeat expansion. Nature genetics 17(1): 65-70.(1997).

[97] Sopher BL, Ladd PD, Pineda VV, Libby RT, Sunkin SM, Hurley JB, et al. CTCF regulates ataxin-7 expression through promotion of a convergently transcribed, antisense noncoding RNA. Neuron 70(6): 1071-84.(2011).

[98] Tan JY, Vance KW, Varela MA, Sirey T, Watson LM, Curtis HJ, et al. Cross-talking noncoding RNAs contribute to cell-specific neurodegeneration in SCA7. Nat Struct Mol Biol 21(11): 955-61.(2014).

[99] Meng L, Ward AJ, Chun S, Bennett CF, Beaudet AL, Rigo F. Towards a therapy for Angelman syndrome by targeting a long non-coding RNA. Nature 518(7539): 409-12.(2015). 


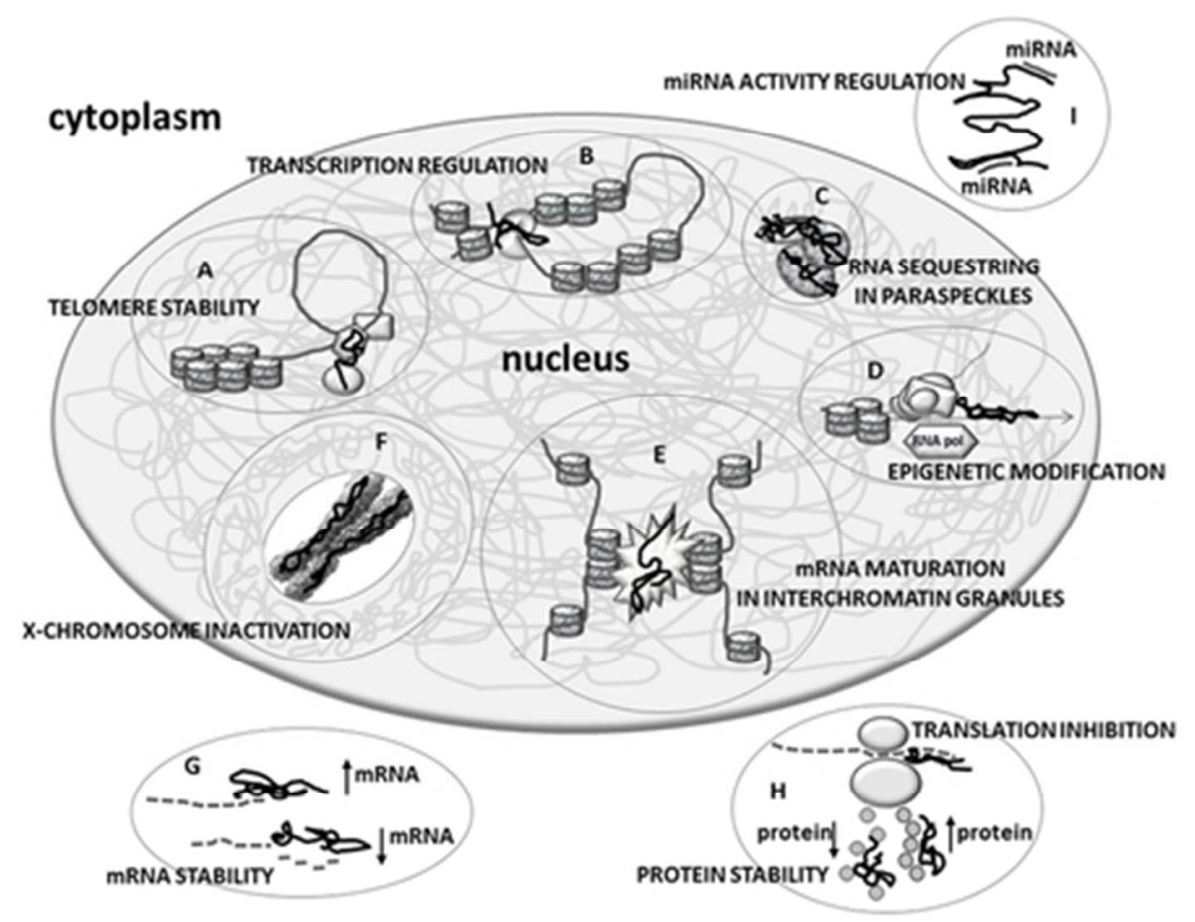

Figure 1: Regulatory mechanisms mediated by IncRNAs in the nucleus and in the cytoplasm Nuclear functions of IncRNAs: A. The IncRNA TERRA maintains telomere stability during DNA replication; B. IncRNAs promote inter- or trans-chromosomal interactions regulating transcription of target loci; C. IncRNAs are able to scaffold nuclear paraspeckles, participating in the regulation of mRNA splicing and maturation; $\mathrm{D}$. IncRNAs can also act in cis or trans to guide epigenetic modifier complexes to targeted sites, by pairing with DNA or mRNA sequences; $E$. IncRNAs can generate inter-chromatin granules involved in pre-mRNA splicing and maturation; F. IncRNAs have a role in X-chromosome inactivation by nuclear architecture modification. Cytoplasmatic functions of IncRNAs: G. IncRNAs can positively or negatively regulate target mRNA stability; $\mathrm{H}$. IncRNAs can regulate protein levels by controlling their translation and stability; I. IncRNAs can interact with miRNAs acting as molecular sponge to modulate their activity . 


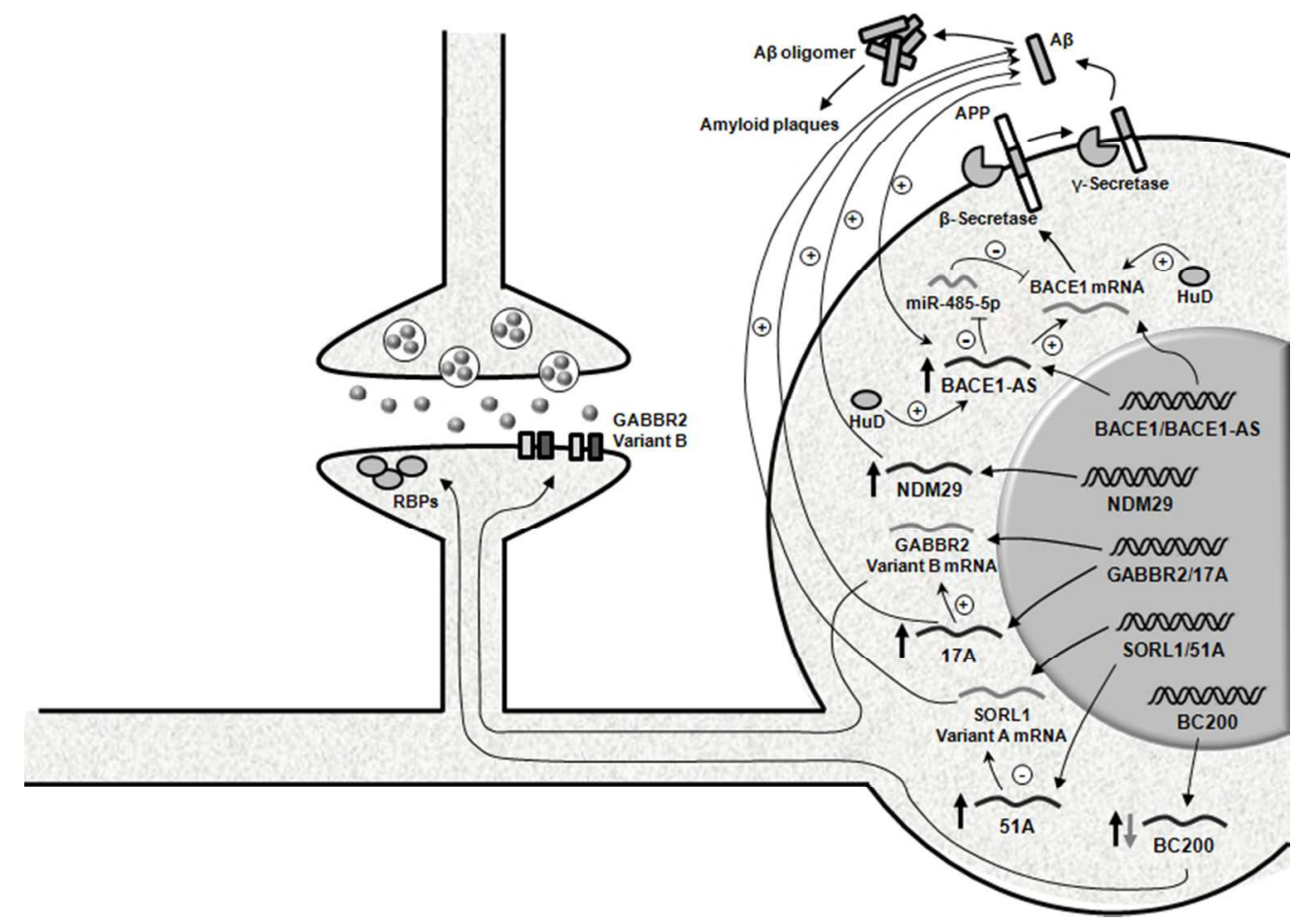

Figure 2: Dysregulated IncRNAs and affected pathways in the pathogenesis of Alzheimer's disease. The BACE1-AS transcript increases the stability of BACE1 mRNA and prevents the binding of miR-485-5p, positively regulating BACE1 and promoting $A \beta 42$ formation. BACE1-AS expression levels are elevated in $A D$ and can be induced by $A B 42$ itself, creating a feed-forward mechanism. Moreover, the RNA-binding protein HuD can bind both BACE1 and BACE1-AS transcripts, increasing their stability. The IncnRNA 17A, which is embedded in an antisense orientation within the GABBR2 gene, is upregulated in AD and favours the synthesis of the GABBR2 receptor splicing isoform $B$ that is defective in transducing the GABAB-dependent intracellular signalling. The up-regulation of $17 \mathrm{~A}$, as well as of the IncRNA NDM29, promotes A $\beta$ secretion with an increase in the $A \beta 42 / A \beta 40$ peptide ratio. The antisense IncRNA $51 A$, located in the first intron of SORL1 gene, promotes the alternative splicing of SORL1 and increases A $\beta$ formation. Finally, the expression of the IncRNA BC200, which acts as a regulator of local protein synthesis at synapses, can be both down- or up-regulated in AD brains. BC200 is able to interact with different RNA-binding proteins known to control mRNA translation in post-synaptic dendritic microdomains. The vertical arrows shown on the left of IncRNAs BACE1-AS, NDM29, 17A and BC200 indicate up- or down-regulation in AD.

$A \beta=$ amyloid-beta peptide; $A P P=$ amyloid precursor protein; $B A C E 1=$ beta-site $A P P$-cleaving enzyme 1 ; BACE1-AS= BACE1 antisense RNA; BC200 = brain cytoplasmic RNA of 200 nucleotides; GABBR2= gammaaminobutyric acid (GABA) B receptor 2; HuD = Hu-antigen D/ELAV like protein 4; NDM29= neuroblastoma differentiation marker 29; RBPs= RNA-binding proteins; SORL1= sortilin-related receptor, L(DLR class) A repeats containing. 
6

7

8

9

artlansons's Disease

11

12

13

14

15

16

Iupţington's Disease

18

19

20

21

22

23

24

25

27

28

29

30

31

32

33

34

36

36
37

38

38
39

40

41

X\$2 $\$$ FXTAS

43

44

45

46

47

pine
$51 \mathrm{~A}$

Up

BC200/BCYRN1 Up/Down

NEAT1 Up (early stages of ALS)

MALAT1

PINK1-AS

UCHL1-AS1

U1 spliceosomal

lncRNA

$\mathrm{Up}$

HTT-AS

Down

BDNF-AS

ABHD11-AS1 Down

HAR1 Down

TUNA Down

TUG Up

LINC000341 Up

RPS20P22 Up

NEAT1 Up

MEG3 Down

DGCR5 Down

LINC000342 Down

FMR1-AS1 Down in FXS/Up in FXTAS

FMR5

FMR6

Down in FXS/FXTAS
Alternative splicing of SORL1 and increases $A \beta$ formation

Regulates translation by interacting with RNA-binding proteins

$[63 ; 64 ; 65-67]$

Role in paraspeckle assembly; binds to TDP-43 and FUS; increased binding to TDP-43 in FTD; expression and localization in paraspeckles increased in ALS motoneurons

Recruits splicing factors to paraspeckles; regulates phosphorylation of splicing factors

$[40 ; 68 ; 69 ; 71]$

Positively regulates the stability of svPINK1 transcript

Positively regulates UCHL1 mRNA translation

Negatively regulates HTT expression

Inhibits BDNF transcrption by recruitment of the PCR2 epigenetic silencing complex

Its overexpression is neuroprotective against an N-terminal fragment of the mutant huntingtin; its knockdown is protoxic

Involved in pluripotency and neural differentiation of embryonic stem cells; its expression in the striatum of HD patients decreases with the increasing of disease grade

Binds the PCR2 epigenetic silencing complex

$-$

$-$

Binds the PCR2 epigenetic silencing complex

Anti-apoptotic function

https://mc04.manuscriptcentral.com/cares

RNA toxic gain-of-function effects; altered binding to RNA-binding proteins 